\title{
Transanal Evisceration of Small Bowel about One Case at the University Hospital Yalgado Ouédraogo of Ouagadougou
}

\author{
Adama Sanou $^{1 *}$, Moussa Bazongo², Edgar Ouangré2, Maurice Zida², \\ Gilbert Patindé Bonkoungou', Rodrique Namékinsba Doamba², Sylvain Wendmi Karfo², \\ Elie Yamba Sawadogo ${ }^{2}$, Nayi Zongo ${ }^{2}$, Si Simon Traoré ${ }^{2}$

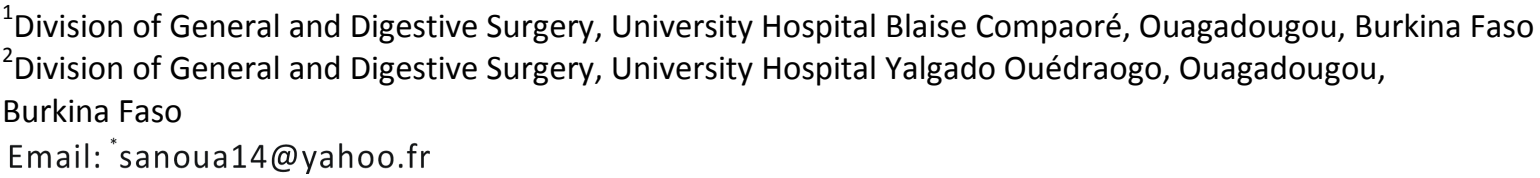

Received 4 May 2016; accepted 2 July 2016; published 5 July 2016

Copyright (C) 2016 by authors and Scientific Research Publishing Inc.

This work is licensed under the Creative Commons Attribution International License (CC BY).

http://creativecommons.org/licenses/by/4.0/

(c) (i) Open Access

\begin{abstract}
Introduction: Transanal evisceration of small bowel is an extremely rare condition that can occur spontaneously or after trauma. Objective: To report a case of Transanal evisceration of small bowel to describe the circumstances of occurrence and our therapeutic attitude. Observation: An 80year-old female patient was received at the visceral Emergency of University Hospital Yalgado Ouédraogo for the outcome of the small intestine by the anus with the waning of a defecation effort. The physical examination of the patient accustomed to evacuation purgation noted, eviscerated the small bowel through the anus, edematous but viable. The preoperative laboratory tests were normal. In emergency, under general anesthesia, a laparotomy was possible to objectify the incarceration of intestinal loops through linear perforation of 5 cenimeter from the anterior surface of the rectosigmoid hinge. We conducted an ileo-ileal resection anastomosis, a suture rectosigmoid breach and anal extraction of small bowel incarcerated measuring 200 centimeter. The evolution was simple. Conclusion: The weakening of the rectal mucosa by repeated purges has certainly been the contributory factor. The surgical treatment must be precocious to avoid extensive intestinal resection.
\end{abstract}

\section{Keywords}

Evisceration, Transanal, Small Bowel, Rectum, Sigmoid

\footnotetext{
*Corresponding author.
} 


\section{Introduction}

The transanal evisceration of small bowel is an extremely rare disease [1]. It can occur spontaneously or following abdominal trauma. The first description was made in 1827 by Sir Benjamin Brodie [1]. Since then several cases have been reported worldwide and recently in Senegal in 2011 [2], in India in 2013 [3], in Spain in 2014 [4]. We report our first case of transanal evisceration of small bowel in order to describe the circumstances of occurrence and our therapeutic approach. We have obtained the informed consent of the patient to the writing of this observation.

\section{Case Report}

An 80-year-old female patient presented on 19-01-2015 to emergency of university hospital Yalgado Ouedraogo with small intestine externalized through the anus for 24 hours. She reported a chronic constipation and he was accustomed to evacuation purges. The externalizing of intestinal loops occurred after pushing effort during defecation. This intestinal loops eviscerated through anus were pink; edematous and covered with false membranes and telluric debris (Figure 1). The rectal mucosa was smooth and presented a perforation of the anterior surface of its upper portion. The diagnosis of transanal evisceration of small intestine was retained. The preoperative laboratory tests were normal. In emergency under general anesthesia a laparotomy was performed. The exploration has noted a loop of small bowel incarcerated through a longitudinal perforation in the anterior face of rectosigmoid. This perforation measured centimeter, with soft and regular edges (Figure 2). There was no mesenteric lymphnode or colic tumor. The abdominal cavity was clean. Eviscerated bowel portion was located 5 centimeter from ileocecal junction and 300 centimeter from the angle of Treitz. We performed, a small bowel resection followed by an immediate end-to-end anastomosis, a suture of the rectosigmoid perforation and drainage of Douglas pouch. The eviscerated intestinal loops were removed by rectal route and measured 200 centimeter. The outcome was simple. She was seen at 30 and 90th days in postoperative control. There were no complaints and clinical examination was normal.

\section{Discussion}

The transanal evisceration of small bowel is extremely rare [1]. The first description was made in 1827 by Sir Benjamin Brodie [1]. Until this period, very few cases have been described sporadically in the world and there are less than 70 cases reported in the literature [4]. Our case is the first observation in Burkina Faso. The mystery that raises our presentation as in other authors remains the etiology of the perforation of the rectosigmoid [5] [6]. The transanal evisceration of small bowel may be secondary to a traumatic perforation of rectosigmoid or as part of an abdominal contusion as reported by Bâ and collaborators [2] or following an impalement [7] [8] or

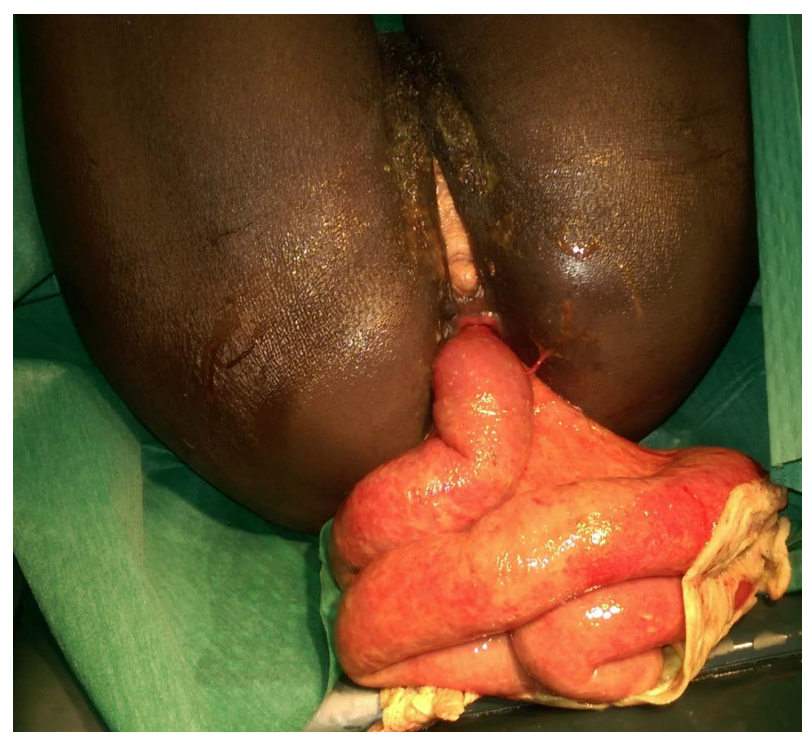

Figure 1. Small intestine loops eviscerated through the anus. 


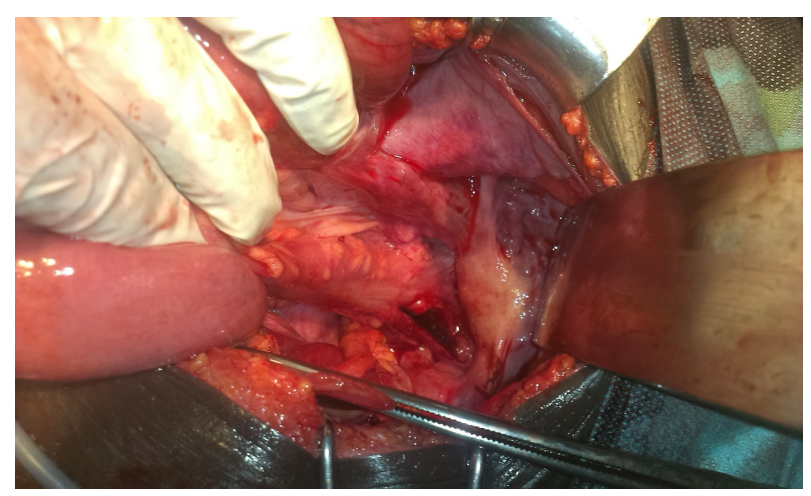

Figure 2. Longitudinal perforation of the anterior surface of rectosigmoid hinge.

a sexual assault in the child [8]. In our case, as in other cases, the transanal evisceration had occurred following a spontaneous recto-sigmoid perforation [6]. In this case some etiologies have been implicated, such as colorectal cancer, diverticular disease or ulcerative colitis [5]. The repeated evacuations purges in our patient were certainly a factor of embrittlement of the rectosigmoid wall, by corrosive effect. In addition, the sharp increase into the rectum and the abdomen pressure during the efforts pushed of defecation has certainly favored the longitudinal perforation of the anterior surface of the rectosigmoid wall as in others authors [5]. Hysterectomy and rectal prolapse were reported as factors weakening anterior wall of rectosigmoid [5]. In our case, the evisceration occurred in people aged over 60 years like that most cases published [1] [6]. Advanced age would be a risk factor for spontaneous transanal evisceration. On the clinical plan, the diagnosis is made at a patient's presenting the intestinal handles outside the anus with a flat belly or of normal volume. In case of vascular lesions, a haemoperitoneum with a state of hemorrhagic shock can be observed like that was the case at BA and collaborators [2]. Exceptionally a generalized acute peritonitis can be associated in case of intestinal necrosis or by defilement of the abdominal cavity by saddles of the perforation of the sigmoid colon. The treatment is not standardized. It must be early and effective to prevent an extended intestinal necrosis that requires making a great sacrifice of intestine. The two-stage surgery including suture perforation with stoma (ileum or colon) followed by a delayed recovery of digestive continuity was the attitude adopted in most of the cases [3]. In our patient we performed a one stage surgery because of the good condition of the patient, a clean abdominal cavity and the stoma refusal of the older people in our context. In all cases the surgical treatment obeyed the principles of digestive surgery. The prognosis of this disease is generally favorable as in our case and in several studies [3]-[5].

\section{Conclusion}

The transanal evisceration by colorectal spontaneous rupture is rare. The etiology is multifactorial. The weakening of the rectal wall by repeated purges evacuation has certainly been the contributory factor in our case. The surgical treatment must be early to avoid extended intestinal resections. It is therefore necessary to raise awareness about the risks of purges evacuations.

\section{Conflicts of Interest}

The authors declare no conflicts of interest related to this article.

\section{References}

[1] Kunin, N., Le Roy, M.-L., Ollivier, F., Morin-Chouarbi, V. and Verbrackel, L. (2005) Prolapsus rectal avec éviscération transanale aiguë du côlon sigmoïde. Gastroentérologie Clinique et Biologique, 29, 478-479. http://dx.doi.org/10.1016/S0399-8320(05)80824-3

[2] Bâ, P.A., Soumah, S.A., Diop, B., Traoré, M.M., Mahdi, C., Mbaye, E.M., et al. (2011) Transanal Small Bowel Loops Evisceration in Child Due to Blunt Trauma: A Case Report. The Pan African Medical Journal, 10, 50.

[3] Kumar, S., Mishra, A., Gautam, S. and Tiwari, S. (2013) Small Bowel Evisceration through the Anus in Rectal Prolapse in an Indian male Patient. BMJ Case Reports. http://dx.doi.org/10.1136/bcr-2013-010411 
[4] Martínez Pérez, A., Torres Sánchez, M.T., Richart Aznar, J.M., Martí Martínez, E.M. and Martínez-Abad, M. (2014) Transanal Evisceration Caused by Rectal Laceration. Annals of Coloproctology, 30, 47. http://dx.doi.org/10.3393/ac.2014.30.1.47

[5] Nari, G.A., Moreno, E. and Ponce, O. (2001) Prolapsus transanal de l’intestin grêle secondaire à une rupture spontanée du rectum. Annales de Chirurgie, 126, 818-820. http://dx.doi.org/10.1016/s0003-3944(01)00612-5

[6] Jeong, J., Park, J.S., Byun, C.G., Yoon, D.S., Sohn, S.K., Lee, Y.H., et al. (2000) Rupture of the Rectosigmoid Colon with Evisceration of the Small Bowel through the Anus. Yonsei Medical Journal, 41, 289-292. http://dx.doi.org/10.3349/ymj.2000.41.2.289

[7] Bronkhorst, M.W., Wilde, J.C., Hamming, J.F. and Heij, H.A. (2007) Anorectal Impalement in a Pediatric Patient with Transanal Evisceration of Small Bowel. Journal of Pediatric Surgery, 42, 23-25. http://dx.doi.org/10.1016/j.jpedsurg.2007.06.010

[8] Vincenzi, R. and Cruz Jr., R.J. (2008) Transanal Small Bowel Evisceration: An Unusual Presentation of Rectal Impalement. European Journal of Trauma and Emergency Surgery, 34, 606-608. http://dx.doi.org/10.1007/s00068-008-7097-x

\section{Submit or recommend next manuscript to SCIRP and we will provide best service for you:}

Accepting pre-submission inquiries through Email, Facebook, Linkedin, Twitter, etc A wide selection of journals (inclusive of 9 subjects, more than 200 journals)

Providing a 24-hour high-quality service

User-friendly online submission system

Fair and swift peer-review system

Efficient typesetting and proofreading procedure

Display of the result of downloads and visits, as well as the number of cited articles

Maximum dissemination of your research work

Submit your manuscript at: http://papersubmission.scirp.org/ 